\title{
PENATAAN KAMPUNG WISATA KREATIF DAGO POJOK BANDUNG
}

\author{
Bayudhira Ramadhana ${ }^{1)}$, Parino Rahardjo ${ }^{2)}$, (rwan Wipranata ${ }^{3)}$ \\ 1)Program Studi S1 PWK, Fakultas Teknik, Universitas Tarumanagara, Bayudhira.345130012@stu.untar.ac.id \\ 2)Program Studi S1 PWK, Fakultas Teknik, Universitas Tarumanagara, parinor@ft.untar.ac.id \\ 3)Program Studi S1 PWK, Fakultas Teknik, Universitas Tarumanagara, irwan_wipranata@yahoo.co.uk
}

\begin{abstract}
Abstrak
Setiap kota di Indonesia pasti terdapat tempat wisata yang memiliki daya tariknya masingmasing, seperti salah satunya adalah jenis wisata edukasi dalam bentuk kesenian, kebudayaan dan ilmu pengetahuan. Penelitian ini dilakukan di Kampung Dago Pojok, Kelurahan Dago, Kecamatan Coblong, Bandung. Permasalahan pada penelitian ini adalah kurangnya fasilitas di dalam kampung wisata Dago Pojok untuk menunjang kebutuhan dasar kenyamanan dan keamanan dari para wisatawan kampung wisata. Tujuan dari penelitian ini adalah untuk mengetahui kondisi sarana dan prasarana penunjang dan mengetahui tingkat keamanan dan kenyamanan wisatawan dalam menjalankan kegiatan wisata. Metode yang digunakan dalam penelitian ini adalah pengumpulan sampel dengan wawancara, observasi lapangan dan penyebaran kuisioner untuk responden, yaitu para wisatawan. Hasil dari penelitian ini diharapkan kontribusi dari masyarakat kampung, organisasi dan pihak pengelola untuk memenuhi kebutuhan dan kenyamanan dari wisatawan, yaitu berupa fasilitas-fasilitas penunjang serta fasilitas tambahan dari perferensi wisatawan berdasarkan wisata edukasi dari wisatawan yang akan dipenuhi.
\end{abstract}

Kata kunci: Fasilitas; Kampung; Kenyamanan dan Keamanan; Pengunjung; Wisata Edukasi

\begin{abstract}
Every City in Indonesia has their own tourist attractions from each potential resources from the tourism destination, some of them have facility issues. Most of the tourism villages use education for their attraction tourism who shares experience and knowledge for the visitors, meanwhile the facilities provided for tourism village to fill their needs and comforts for visitors are limited. This research was held in Kampung Dago Pojok, Kelurahan Dago, Kecamatan Coblong, Bandung. The problem in this situation is the lack of facilities inside the tourism village of Dago Pojok from the perspective of basic needs, comforts, and safety of visitors. Method that is used is description which explained the needs and today's existing through picture from the field observation, perception, and tourists' preference from the questionnaire distributions and interviews. The result from this research is the contribution of the village's society, organization, and the management to fulfill the needs and comforts of visitors, in the form of support facilities and additional facilities that will be fulfilled with the preference of educational tourism from the visitors.
\end{abstract}

Keywords: Comfort; Education Tourism; Facility; Village Tourism; Visitor

\section{PENDAHULUAN}

Indonesia merupakan negara yang memiliki beraneka ragam pariwisata yang tentu saja menjadi pendapatan devisa yang tidak kecil jumlahnya. Dengan dasar bentuk negara kepulauan maka banyak wisata-wisata di Indonesia yang menyediakan keindahan pantai serta pulau-pulau wisata yang menjual keindahan alamnya yang alami. Sehingga sangat besar devisa pemasukan negara dari para wisatawan mancanegara yang berkunjung untuk berwisata ke Indonesia untuk menikmati keindahan alam dan kekayaan kebudayaan yang dimiliki negara ini.

Kampung wisata merupakan suatu bentuk integrasi yang direncanakan oleh pemerintah serta pelaku masyarakat yang dilengkapi dengan fasilitas-fasilitas penunjang dalam tatanan kehidupan masyarakat. Tetapi dalam hal ini fasilitas serta perencanaan yang disajikan dalam struktur kehidupan masyarakat 
adalah seni budaya, serta tradisi yang berlaku di daerah tersebut. Kampung wisata bertujuan untuk menghibur wisatawan, memberikan pelajaran-pelajaran baru dalam hal sejarah dan kesenian untuk melestarikan kebudayaan terutama di daerah kampung tersebut.

Kegiatan kesenian yang berasal dari beberapa khas kebudayaan yang menjadi daya tarik utama dari Kampung Wisata Kreatif Dago Pojok, serta banyak juga pengunjung dan wisatawan yang datang dari dalam maupun mancanegara, maka banyak hal yang harus diperhatikan. Seperti kondisi sarana dan prasarana kawasan penunjang kampung wisata Dago Pojok yang masih sangat kurang untuk mendukung adanya aktivitas besar di dalam kampung.

Ada juga masalah pengunjung yang menurun sehingga sangat mempengaruhi mata pencaharian masyarakat di dalam kampung, dengan demikian masih banyak yang masih harus ditata dari kampung wisata tersebut, maka dari itu penulis tertarik untuk melakukan penataan kawasan Kampung Wisata Dago Pojok Bandung. Tujuan dari penelitian ini adalah mengetahui fasilitas yang dibutuhkan dari para pengunjung, mengetahui tingkat keamanan dan kenyamanan pada pengunjung dalam berkunjung ke kampung wisata, membuat konsep dan rencana penataan yang sesuai dengan kebutuhan Kampung Wisata Kreatif Dago Pojok.

\section{KAJIAN LITERATUR}

Aktivitas wisata edukasi meliputi; konverensi, penelitian, pertukaran pelajar nasional dan internasional, kunjungan sekolah, sekolah bahasa, dan wisata studi, yang diorganisasi secara baik secara formal maupun nonformal, dengan tujuan wisata alam maupun buatan. (Jafari dan Ritchie 1981)

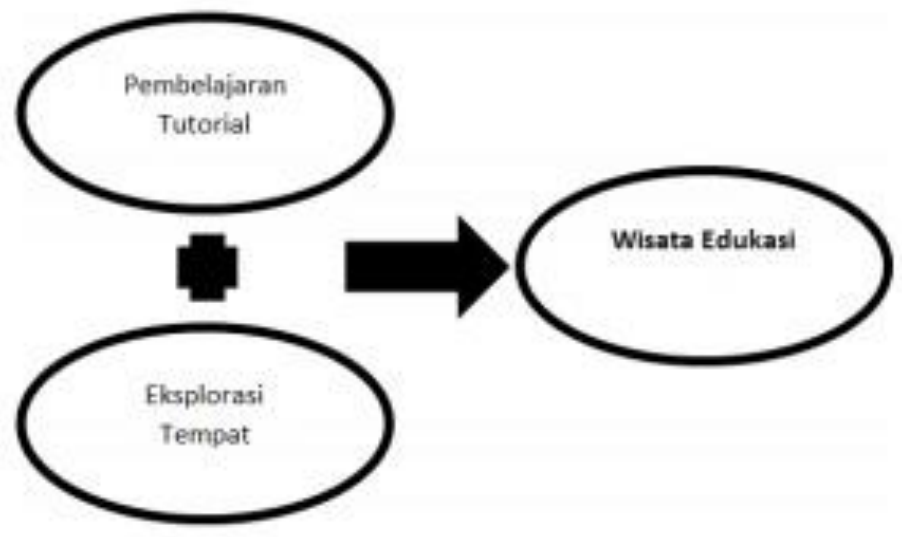

Gambar 1. Diagram Tabel Edukasi

Sumber: Simond, 1983

\section{Tutorial}

Tutorial adalah bimbingan pembelajaran dalam bentuk pemberian bimbingan, bantuan, petunjuk arahan dan motivasi agar para pengunjung belajar secara efisien dan efektif.

Pengaplikasian konsep pembelajaran tutorial dapat dimulai dengan mempersiapkan kontenkonten informasi apa saja yang ingin disampaikan kepada para wisatawan. Dikaitkan dengan daya tarik yang dimiliki oleh objek wisata masing-masing.

a. Menyampaikan pengetahuan dasar mengenai konten edukasi yang disiapkan berdasarkan dari potensi atau daya tarik wisata.

b. Dalam upaya menciptakan kegiatan belajar yang aktif, maka pihak pengelola harus mampu menyediakan pemandu yang atraktif dan komunikatif.

c. Untuk menunjang kegiatan pembelajaran wisata yang menarik maka pengelola wisata dapat menambahkan media pendukung, seperti gambar, foto, ataupun ilustrasi lainnya. Sehingga hal ini mampu meningkatkan pemahaman wisatawan mengenai konten informasi yang disampaikan. 


\section{Eksporasi}

Tujuan dari metode ekplorasi tempat ini adalah agar pengunjung dapat mengenal dan melihat secara langsung objek yang disampaikan dalam pembelajaran tutorial sebelumnya.

Hal yang perlu diperhatikan dalam hal ini adalah menciptakan sirkulasi alur pergerakan wisatawan, dimulai dari masuk hingga keluar. Tujuan daripada sirkulasi ini adalah untuk menciptakan pergerakan wisatawan yang tertib dan lancar, wisatawan juga diarahkan untuk mengeksplorasi seluruh tempat kegiatan dan fasilitas yang terdapat di dalam area wisata. (Simond,1983)

\section{METODE}

Pendekatan yang dilakukan dalam penelitian ini menggunakan metode kualitatif dengan beberapa cara untuk mendapatkan data. Pengumpulan data primer dilakukan dengan cara:

1. Observasi lapangan

Mengumpulkan data dan informasi melalui pengamatan langsung atau survey ke objek studi penelitian yaitu Kampung Wisata Dago Pojok berdasarkan kondisi eksisting yang ada agar dapat menggambarkan dan mendeskripsikan kondisi dari kampung wisata.

a. Dokumentasi

Metode pengambilan data dalam bentuk rekaman secara visual atau foto untuk membantu menggambarkan secara nyata kondisi kampung wisata berupa foto atau video.

b. Wawancara

Metode pengumpulan data dengan mengajukan pertanyaan secara lisan kepada para stakeholder atau pemangku kepentingan di kampung wisata. Pemangku kepentingan yang dimaksud adalah warga kampung, organisasi dalam kampung, pengusaha di dalam kampung, pengelola kampung wisata, para seniman, dan wisatawan yang berkunjung. Tujuan dari wawancara adalah untuk mengetahui permasalahan atau isu yang ada di luar dan dalam kampung, mengetahui sejarah dari kampung, mengetahui keinginan atau target dengan adanya kampung wisata.

c. Kuesioner

Metode pengumpulan data dengan membuat daftar pertanyaan secara tertulis dan memberikan pertayaan kepada responden yang kemudian dijawab. Pertanyaan akan diajukan kepada para pengunjung mengenai kondisi eksisting Kampung Wisata Kreatif Dago Pojok mulai dari prasarana dan sarana dalam kampung, serta tingkat kenyamanan dan keamanan dari para pengunjung, yang kemudian akan berpengaruh pada rencana penataan kawasan Kampung Wisata Kreatif Dago Pojok.

d. Sampling

Sampel dalam penelitian ini menggunakan purposive sampling, yaitu pemilihan sampel dengan suatu karakteristik yang menjadi perbedaan. Seperti contohnya sampel yang akan diambil dengan minimal lulus tingkat pendidikan Sekolah Dasar.

\section{Pengumpulan data sekunder dengan cara:}

Pengumpalan data dari instansi pemerintah maupun non pemerintah yang terkait. Hasil yang didapatkan dari survey sekunder ini adalah berupa uraian, data angka, dan peta objek studi yaitu Kampung Wisata Dago Pojok. Selain itu pengempulan data sekunder juga dapat dilakukan dengan melalui internet sehingga dapat memperoleh data-data pendukung untuk penelitian yang akan dilakukan.

Berikut merupakan profil objek studi kawasan Kampung Wisata Kreatif Dago Pojok Nama: Kampung Dago Pojok

Lokasi: Jalan Dago Pojok RW.3, Kelurahan Dago, Kecamatan Coblong, Kota Bandung 


\section{Batas Wilayah: \\ - Utara: Aliran Sungai Cikapundung \\ - Selatan: Lahan Universitas Padjajaran \\ - Timur: Perumahan Bukit Dago \\ - Barat : Perumahan Kampung Padi}

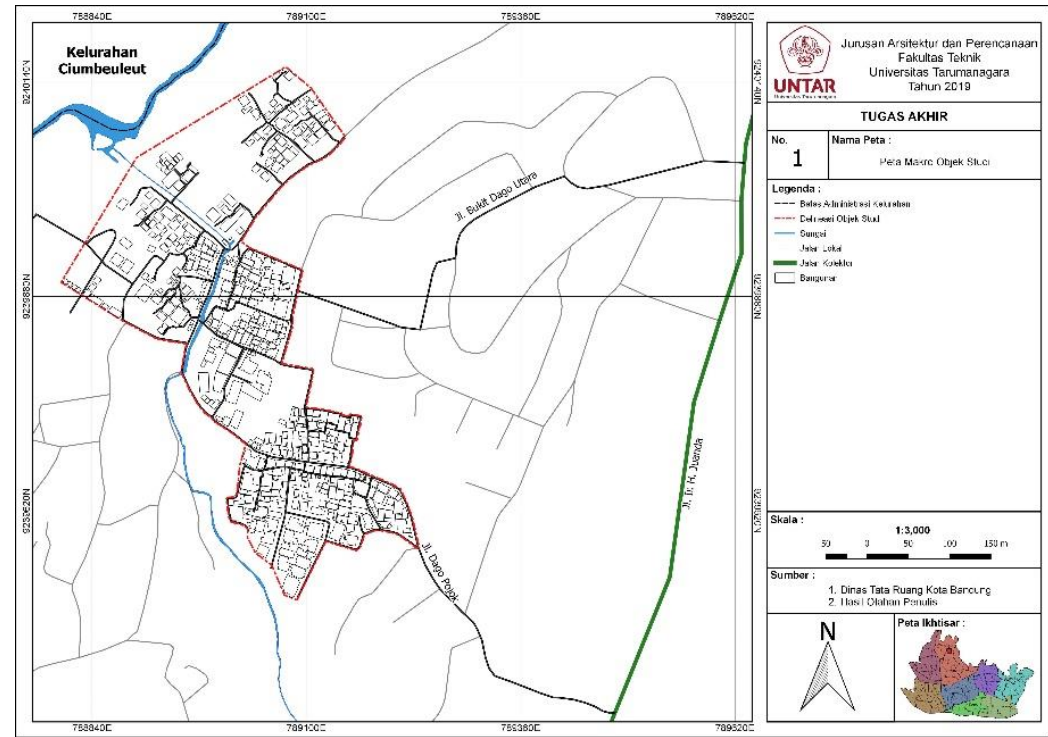

Gambar 2. Peta Objek Studi

Sumber: Penulis, 2019

\section{DISKUSI DAN HASIL}

Objek studi dengan total luasan 10,63 hektar memiliki fungsi lahan yang terbagi-bagi di dalamnya. Berikut adalah tabel penggunaan lahan di dalam objek studi

Tabel 1. Penggunaan Lahan Objek Studi

\begin{tabular}{clcc} 
No. & Penggunaan Lahan & Luas (ha) & Persentase \\
\hline 1 & Permukiman & 6,93 & $65,2 \%$ \\
\hline 2 & RTH & 2,31 & $21,7 \%$ \\
\hline 3 & Perkebunan & 0,082 & $0,8 \%$ \\
\hline 4 & Fasilitas & 0,1 & $2,8 \%$ \\
\hline & Total & 10,63 & $100 \%$ \\
\hline
\end{tabular}

Sumber: Penulis, 2019

\section{Analisis Tapak}

Land Use

Berdasarkan dari pembagian tata guna lahan yang berada di dalam objek studi, permukiman memiliki luasan lahan yang paling besar yaitu sebesar $65,2 \%$ dari $100 \%$, kemudian diikuti lahan terbesar kedua adalah ruang terbuka hijau (RTH) sebesar $21,7 \%$.

\section{Prasarana}

Berikut adalah kondisi prasarana yang ada di Kampung Dago Pojok: 
Tabel 2. Kondisi Prasarana

\begin{tabular}{|c|c|c|c|c|}
\hline No & Prasarana & Permasalahan & Ketentuan & Kesimpulan \\
\hline 1 & Jaringan Jalan & $\begin{array}{l}\text { Kondisi Jalan Dago } \\
\text { Pojok yang rusak }\end{array}$ & $\begin{array}{l}\text { Untuk kenyamanan akses } \\
\text { pengunjung masuk dan keluar, } \\
\text { kondisi jalan harus memadai dan } \\
\text { rapi }\end{array}$ & Belum Baik \\
\hline 2 & Jalan Setapak & $\begin{array}{l}\text { Tidak adanya jalan } \\
\text { setapak di } \\
\text { sepanjang jalan } \\
\text { Dago Pojok }\end{array}$ & $\begin{array}{l}\text { Berdasarkan ketentuan kebutuhan } \\
\text { fasilitas jalan setapak untuk wisata } \\
\text { maka dibutuhkan pembuatan } 2 \text { buah } \\
\text { trotoar dengan kapasitas lebarnya } 1 \\
\text { orang adalah } 1,62 \mathrm{~m}^{2}\end{array}$ & Belum Baik \\
\hline 3 & Saluran Air & - & $\begin{array}{l}\text { Berdasarkan Peraturan Menteri } \\
\text { Pekerjaan Umum tahun 2014, } \\
\text { drainase harus ada di permukiman } \\
\text { yang terletak di kota, serta aliran air } \\
\text { diarahkan tidak boleh ke aliran } \\
\text { sungai dikarenakan dapat } \\
\text { menambah beban volume sungai }\end{array}$ & Sudah Baik \\
\hline 4 & Air Bersih & - & $\begin{array}{l}\text { Kriteria air bersih: } \\
\text { 1. Jernih } \\
\text { 2. Tidak Berwarna } \\
\text { 3. Tidak Berasa } \\
\text { 4. Tidak Berbau }\end{array}$ & Sudah Baik \\
\hline 5 & Listrik & $\begin{array}{l}\text { Keadaan kabel listrik } \\
\text { yang masih } \\
\text { berantakan, serta } \\
\text { ketinggian kabel } \\
\text { listrik yang dekat } \\
\text { dengan bangunan } \\
\text { perumahan }\end{array}$ & $\begin{array}{l}\text { Berdasarkan dari Peraturan Menteri } \\
\text { Negara Perumahan Rakyat Tentang } \\
\text { Teknis tahun no. } 4 \text { 2011, } \\
\text { pemasangan kelistrikan seperti tiang } \\
\text { listrik dan kabel harus dilakukan } \\
\text { dengan aman dan dengan estetika } \\
\text { yang baik. }\end{array}$ & Belum Baik \\
\hline 6 & Penerangan & $\begin{array}{l}\text { Penerangan yang } \\
\text { masih minim di } \\
\text { Jalan Dago Pojok } \\
\text { serta di dalam } \\
\text { perkampungan }\end{array}$ & $\begin{array}{l}\text { Berdasarkan dari Peraturan Menteri } \\
\text { Negara Perumahan Rakyat Tentang } \\
\text { Teknis tahun no. } 4 \text { 2011, Penerangan } \\
\text { di dalam kegiatan permukiman } \\
\text { harus dilakukan secara merata }\end{array}$ & Belum Baik \\
\hline
\end{tabular}

Sumber: Penulis, 2019

Berdasarkan dari tabel diatas ada beberapa prasarana yang masih harus diperhatikan yaitu jaringan jalan, jalan setapak, listrik, dan juga penerangan. Sedangkan untuk saluran air dan air bersih berdasarkan dari kriteria sudah baik berdasarkan peraturan dan kriteria yang sudah ditentukan.

\section{Sarana}

Berikut adalah sarana yang ada di Kampung Wisata Kreatif Dago Pojok: 
Tabel 3. Kondisi Sarana

\begin{tabular}{|c|c|c|c|c|}
\hline No & Fasilitas & Kondisi & Ketersediaan & Usulan \\
\hline 1 & Area Parkir & Tidak Permanen & Belum Baik & $\begin{array}{l}\text { Apabila kedepannya disesuaikan dengan peningkatan } \\
\text { jumlah penunjung dan frekuensi kunjungan yang lebih } \\
\text { sering, maka dibutuhkan pembangunan lahan parkir } \\
\text { khusus kegiatan kampung wisata dengan } \\
\text { kepengurusan dari kampung wisata. }\end{array}$ \\
\hline 2 & Toilet & Permanen & Belum Baik & $\begin{array}{l}\text { Dibutuhkan pembangunan jumlah toilet umum lagi } \\
\text { untuk memenuhi kebutuhan pengunjung berdasarkan } \\
\text { dari luas kegiatan wisata dalam kampung yang luas } \\
\text { dan tersebar. }\end{array}$ \\
\hline 3 & Homestay & Permanen & Cukup & $\begin{array}{l}\text { Penginapan yang berdasarkan kontribusi warga } \\
\text { kampung yang mendukung aktivitas Kampung Wisata } \\
\text { Kreatif Dago Pojok sudah baik, berdasarkan dari } \\
\text { ketersediaan rumah yang dapat ditinggali selalu } \\
\text { cukup. }\end{array}$ \\
\hline 4 & Warung & Permanen & Cukup & $\begin{array}{l}\text { Warung yang tersedia sudah cukup baik dikarenakan } \\
\text { lokasi warung yang tidak menghalangi jalan karena } \\
\text { sudah menyisihkan sebagian lahan dari rumahnya } \\
\text { untuk berjualan. }\end{array}$ \\
\hline 5 & Warteg & Tidak Permanen & Cukup & $\begin{array}{l}\text { Masih dibutuhkan penataan yang lebih baik } \\
\text { dikarenakan masih ada beberapa warteg yang } \\
\text { berjualan di pinggir jalan yang dibangun hanya } \\
\text { seadanya dari kayu yang mempengaruhi kenyamanan } \\
\text { pengunjung. }\end{array}$ \\
\hline 6 & $\begin{array}{l}\text { Balai } \\
\text { Pertemuan }\end{array}$ & Tidak Permanen & Cukup & $\begin{array}{l}\text { Balai pertemuan yang sudah ada di dalam kampung } \\
\text { wisata sudah cukup, dikarenakan luasan yang } \\
\text { memadai serta fungsi balai pertemuan yang tidak } \\
\text { terus menerus dipakai dalam kegiatan kampung } \\
\text { wisata dengan lokasi kedua balai pertemuan yang } \\
\text { sudah cukup dapat dijangkau }\end{array}$ \\
\hline 7 & Pos Keamanan & - & Belum Baik & $\begin{array}{l}\text { Diperlukan pembangunan pos keamanan di beberapa } \\
\text { titik dalam kampung untuk meminimalisir dan } \\
\text { mencegah tindakan kriminal di dalam kampung } \\
\text { wisata. }\end{array}$ \\
\hline 8 & Papan Petunjuk & - & Belum Baik & $\begin{array}{l}\text { Diperlukan pemasangan papan petunjuk di banyak } \\
\text { titik untuk mengarahkan pengunjung ke kegiatan- } \\
\text { kegiatan seni. }\end{array}$ \\
\hline
\end{tabular}

Sumber: Penulis, 2019

Berdasarkan tabel diatas area parkir dan toilet sudah tersedia tetapi masih kurang baik kondisinya, sedangkan pos keamanan dan papan petunjuk belum tersedia di kampung wisata.

\section{Analisis Benchmarking}

Berikut adalah 2 objek pembanding denga kegiatannya yang diambil untuk dijadikan perbandingan dengan Kampung Wisata Kreatif Dago Pojok: 
Tabel 4. Objek Pembanding

No Nama Wisata Lokasi

Kegiatan Wisata

a. Melihat rumah dan bangunan tua

Jalan Maspati V, Bubutan, Kota Surabaya b. Pagelaran Kesenian

c. Proses daur ulang sampah

d. Proses mengolah limbah air e. Urban Farming

a. Home Stay

b. Outbond

c. Lukis

Desa Donokerto,

d. Batik

Kecamatan Turi,

e. Belajar Musik

f. Pagelaran Tari-tarian

g. Kegiatan-kegiatan sawah

Sumber: Penulis, 2019

Berdasarkan dari kegiatan yang ada di tabel, kampung dan desa wisata diatas menerapkan konsep wisata edukasi. Berikut adalah tabel fasilitas penunjang yang dimiliki dan di bandingkan dengan objek studi Kampung Wisata Kreatif Dago Pojok:

Tabel 5. Usulan Perbandingan Fasilitas

\begin{tabular}{|c|c|c|c|c|}
\hline \multirow[b]{2}{*}{ No. } & \multirow[b]{2}{*}{ Fasilitas } & \multicolumn{2}{|c|}{ Objek Pembanding } & \multirow{2}{*}{$\begin{array}{c}\text { Objek Studi } \\
\text { Kampung Wisata } \\
\text { Kreatif Dago Pojok }\end{array}$} \\
\hline & & $\begin{array}{c}\text { Kampung Lawas } \\
\text { Maspati }\end{array}$ & $\begin{array}{c}\text { Desa Wisata } \\
\text { Kembang Arum }\end{array}$ & \\
\hline 1 & Pintu Gerbang & v & v & - \\
\hline 2 & Loket & v & $v$ & - \\
\hline 3 & Pusat Informasi & v & $\checkmark$ & - \\
\hline 4 & Pos Jaga & v & $\checkmark$ & - \\
\hline 5 & Masjid/ Mushola & $\mathrm{v}$ & $\mathrm{v}$ & $\mathrm{v}$ \\
\hline 6 & Toilet Umum & - & $v$ & $\sqrt{ }$ \\
\hline 7 & Papan Petunjuk & $v$ & $\checkmark$ & - \\
\hline 8 & Toko Souvenir & v & $v$ & - \\
\hline 9 & Panggung & v & v & - \\
\hline 10 & Balai Pertemuan & $\mathrm{v}$ & $\mathrm{v}$ & $\mathrm{v}$ \\
\hline 12 & $\begin{array}{l}\text { Home Stay } \\
\text { Rumah Makan }\end{array}$ & - & $v$ & v \\
\hline 13 & Khas & - & $\mathrm{v}$ & - \\
\hline 14 & Perpusatakaan & $\mathrm{v}$ & $\mathrm{v}$ & - \\
\hline 15 & $\begin{array}{l}\text { Gazebo } \\
\text { Penyewaan }\end{array}$ & $v$ & v & - \\
\hline 16 & $\begin{array}{l}\text { Pakaian/ } \\
\text { AsesorisAdat }\end{array}$ & $\mathrm{v}$ & $\mathrm{v}$ & - \\
\hline 17 & Pondok Penelitian & - & $\mathrm{v}$ & - \\
\hline
\end{tabular}

Sumber: Penulis, 2019 
Masih banyak yang harus dilengkapi oleh Kampung Wisata Kreatif Dago Pojok untuk memaksimalkan fasilitas penunjang wisata, fasilitas yang dibutuhkan adalah pintu gerbang, loket, pusat informasi, pos jaga papan petunjuk, toko souvenir, panggung, rumah makan khas, perpustakaan, gazebo, ruang ganti, dan pondok penelitian.

\section{Analisis Persepsi dan Perferensi}

Dari analisis persepsi, analisis hubungan dan kebutuhan, serta preferensi pengunjung diatas maka penulis memiliki kesimpulan tentang fasilitas pendukung dan prasarana di kawasan Kampung Wisata Kreatif Dago Pojok sebagai berikut :

1. Perlu adanya perbaikan rencana perbaikan jalan, tiang dan kabel listrik, dan titik penerangan jalan.

2. Perlu ditambahkan gerbang, loket, pusat informasi, pos jaga, papan petunjuk, toko souvenir, panggung, rumah makan khas, perpustakaan, ruang ganti, dan gazebo.

\section{Analisis Kebutuhan Ruang}

Berdasarkan dari data yang diperoleh dari pengelola kampung wisata diketahui bahwa pengunjung yang datang ke kampung wisata mengalami peningkatan per tahunnya. Berikut merupakan perhitungan proyeksi pengunjung pada 10 tahun kedepan menggunakan metode geometrik:

Tabel 6. Proyeksi Pengunjung

\begin{tabular}{ccc}
\hline No & Tahun & Jumlah Pengunjung \\
\hline 1 & 2013 & 1,215 \\
\hline 2 & 2014 & 1,364 \\
\hline 3 & 2015 & 1,536 \\
\hline 4 & 2016 & 1,678 \\
\hline 5 & 2017 & 1,948 \\
\hline 6 & 2018 & 2,206 \\
\hline 7 & 2019 & 2498 \\
\hline 8 & 2020 & 2829 \\
\hline 9 & 2021 & 3204 \\
\hline 10 & 2022 & 3628 \\
\hline 11 & 2023 & 4109 \\
\hline 12 & 2024 & 4653 \\
\hline 13 & 2025 & 5269 \\
\hline 14 & 2026 & 5967 \\
\hline 15 & 2027 & 6757 \\
\hline 16 & 2028 & 7652 \\
\hline
\end{tabular}

Sumber: Penulis, 2019

Berdasarakan dari perhitungan proyeksi pengunjung maka pada tahun 2028 jumlah pengunjung akan mencapai 7,652 orang, yang kemudian akan menjadi dasar dari perhitungan kebutuhan ruang. 
Tabel 7. Usulan Standar Kebutuhan Ruang

\begin{tabular}{clcc}
\hline No. & \multicolumn{1}{c}{ Fasilitas } & Asumsi & Hasil \\
\hline 1 & Parkir & Persepsi dan SNI & $387 \mathrm{~m}^{2}$ \\
\hline 2 & Penginapan & Persepsi \& Eksisting & 143 orang \\
\hline 3 & Toilet & Standar Neufort & $23 \mathrm{~m}^{2}$ \\
\hline 4 & Ruang Ganti & Standar Neufort & $20 \mathrm{~m}^{2}$ \\
\hline 5 & Pusat Informasi & Standar Neufort & $6 \mathrm{~m}^{2}$ \\
\hline 6 & Pos Keamanan & Standar Neufort & $7,5 \mathrm{~m}^{2}$ \\
\hline 7 & Toko Souvenir & Persepsi dan SNI & $60 \mathrm{~m}^{2}$ \\
\hline 8 & Panggung & Standar Panggung Pagelaran & $8 \times 6$ \\
\hline 9 & Rumah Makan & Asumsi pribadi dan Perferensi & $200 \mathrm{~m}^{2}$ \\
\hline 10 & Gazebo & Standar NAD, 2002 & $14 \mathrm{unit}^{2}$ \\
\hline 11 & Perpustakaan & Standar SNI dan Perferensi & $143 \mathrm{~m}^{2}$ \\
\hline 12 & Pos Kesehatan & Standar Neufort & $8 \mathrm{~m}$ \\
\hline 13 & RTNH & Peraturan Menteri Pekerjaan Umum & $2,000 \mathrm{~m}^{2}$ \\
\hline
\end{tabular}

Sumber: Penulis, 2019

Standar yang digunakan untuk perhitungan rencana kebutuhan ruang adalah standar SNI, standar Neufort arsitektur, Standar NAD, dan Peraturan Menteri Pekerjaan Umum.

Tabel 8. Usulan Konsep Land Use

\begin{tabular}{clcc}
\hline No. & Penggunaan Lahan & Luasan (ha) & Persentase \\
\hline 1 & Permukiman & 5.8 & $55 \%$ \\
\hline 2 & RTH & 2.95 & $28 \%$ \\
\hline 3 & Sawah & 0.97 & $9 \%$ \\
\hline 4 & Kebun & 0.05 & $0.4 \%$ \\
\hline 5 & Fasilitas & 0.55 & $5 \%$ \\
\hline 6 & Kegiatan Kesenian & 0.12 & $1 \%$ \\
\hline 7 & Relokasi & 0.2 & $2 \%$ \\
\hline & Total & 10.63 & $100 \%$ \\
\hline
\end{tabular}

Berdasarkan dari tabel diatas luasan penggunaan lahan terbesar adalah permukiman dengan adanya tambahan kegiatan kesenian dan zona relokasi.

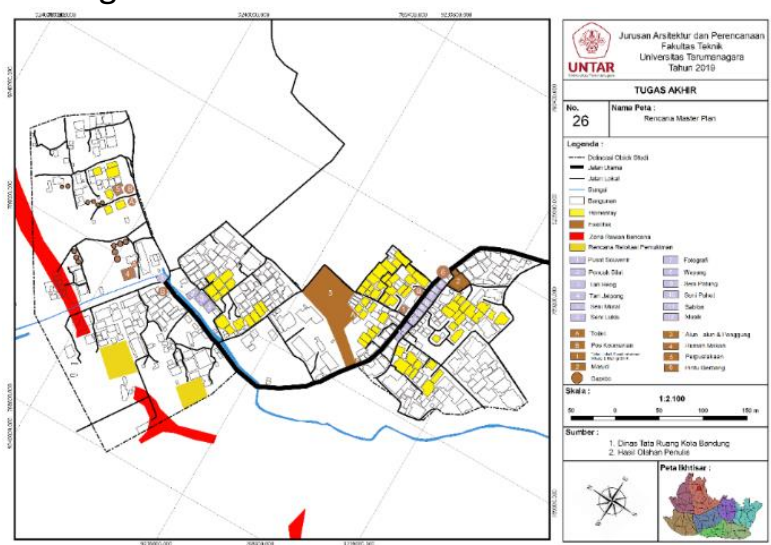

Gambar 3. Peta Masterplan

Sumber: Penulis, 2019 


\section{KESIMPULAN DAN SARAN}

\section{Kesimpulan}

- Mengetahui tingkat kepentingan dan kepuasan dari pengunjung mengenai fasilitas di kampung wisata melalui metode observasi dan penyebaran kuisioner

- Menentukan konsep berdasarkan potensi dan kegiatan wisata yang dapat menjadi acuan menentukan kebutuhan ruang yang dilengkapi dengan teori standar arsitektur dan SNI

- Mengaplikasikan penjelasan mengenai kebutuhan ruang maka direncanakan masterplan dalam bentuk peta

\section{Saran}

- Pemerintah Kota Bandung dan juga pariwisata harus lebih peka terhadap potensi yang dimiliki warga kampung yang dapat menjadi wadah wisata dengan konsep edukasi yang dapat melestarikan kebudayaan dan kesenian.

- Masih banyak yang dapat dilakukan oleh warga kampung wisata seperti membuat UKM dari potensi yang dimiliki kampung

- Adanya RTNH yang dapat memotivasi warga kampung untuk lebih semangat dalam mengadakan promosi dan meningkatkan kualistas dari kampung wisata.

- Pengelola dan pihak seniman harus lebih berusaha untuk mengajak warga kampung untuk berkontribusi untuk perkembangan Kampung Wisata Kreatif Dago Pojok

\section{REFERENSI}

Departemen Kebudayaan dan Pariwisata dan WWF Indonesia. 2009. Prinsip dan Kriteria Ekowisata Berbasis Masyarakat. Jakarta.

Ernawati, dkk. (2006). Pengaruh Sosial Budaya Ekowisata Berbasis MasyarakatTerhadap Masyarakat lokal di Taman Nasional Gunung Halimun, [Penelitian], Universitas Sebelas Maret, Solo.

Jafari, J., \& Ritchie, J. R. B. (1981). Toward a Framework for Tourism Education: Problems and Prospects. Annals of Tourism Research,8 (1), 13-34

Maharani, I. (2010). Tinjauan Umum Kampung Wisata. Kampung Wiasata, 31-44.

Mousavi, S. S., Doratli, N., Mousavi, S. N., \& Moradiahari, F. (2016). Defining Cultural Tourism. International Converence on Civil, Architecture and Sustainable Development, 70-74.

Sharpley, R. (2000). Tourism and Sustainable Development: Exploring the Theorectical Divice. Journal of Sustainable Tourism

Spillane, J. (1994). Pariwisata Indonesia (Siasat Ekonomi dan Rekayasa Kebudayaan). Yogyakarta: Kanisius.

Sulaeman, M. (1998). Ilmu Budaya Dasar Suatu Pengantar, Bandung: Rafika Aditama.

Yoeti, H, O. A. (1997). Perencanaan dan Pengembangan Pariwisata. Jakarta: PT Pradnya Paramita Wijayanti, A. (2017a). Analisis Dampak Pengembangan Desa Wisata Kembang Arum Terhadap Perekonomian Masyarakat Lokal. Tesis. Sarjana Wiyata Tamansiswa Yogyakarta 